\title{
Integration of Well Logs and Seismic Data for Hydrocarbon Volumetric Analysis in D- One Field of the Niger Delta Region, Nigeria
}

\author{
${ }^{1}$ UMEANO, JC; ${ }^{2}$ EMUJAKPORUE, G *30KUJAGU, DC \\ ${ }^{I}$ Center for Petroleum Geosciences, ${ }^{2}$ Department of Physics, ${ }^{3}$ Department of Geology, University of Port Harcourt, Choba, Nigeria \\ *Corresponding Author Email: diepiriye.okujagu@uniport.edu.ng; joan.chygaga@gmail.com; godwin.emujakporue@uniport.edu.ng
}

\begin{abstract}
The study was carried out on an onshore Niger Delta field using seven wells with the objectives of identifying possible reservoir units with potential to contain oil or gas using well logs and seismic data sets. Petrophysical properties analysis revealed two Hydrocarbon bearing reservoirs ranging from $5000 \mathrm{ft}-8000 \mathrm{ft}$, with volume of shale (Vsh) ranging from $4.3 \%-43.9 \%$. The total porosity ranged from $25.9 \%-34.7 \%$, while effective porosity ranged from $17.7 \%-33.2 \%$, indicating good porosities for the reservoirs. Net-to-Gross ranged from $0.720-0.980$ with water saturation ranging from $19.87 \%-29.07 \%$, while hydrocarbon saturation ranged from $70.93 \%-78.86 \%$ of gas in the reservoirs. For the volumetric analysis of the two reservoirs modelled, a STOIIP ranging from 614MMSTB - 1054MMSTB was obtained, while the recoverable Oil was estimated between 215-369MMSTB. We can infer that the two reservoirs mapped, correlated and modelled across the seven wells has a respectable HC potential.
\end{abstract}

DOI: DOI: https://dx.doi.org/10.4314/jasem.v23i11.22

Copyright: Copyright (c) 2019 Umeano et al. This is an open access article distributed under the Creative Commons Attribution License (CCL), which permits unrestricted use, distribution, and reproduction in any medium, provided the original work is properly cited.

Dates: Received: 07 October 2019; Revised: 11 November 2019; 24 November 2019

Key words: Well Logs, Seismic Data, Volumetric Analysis, Niger Delta

Increasing demand for oil and gas worldwide has caused an increase in exploration and development in pre-explored areas around the world such as the Niger Delta. Consequently, more detailed methods apart from structural approach are being developed which include the characterization of the hydrocarbon reservoirs. Aizebeokha and Olayinka, (2011) proposed the combination of formation evaluation, volume of hydrocarbon in place, stratigraphic and structural framework in reservoir heterogeneity characterization for effective determination of permeability, fluid distribution and hydrocarbon in place (Adetoye, 2009) Mapped lateral boundaries of reservoirs using reflection attributes of subsurface maps.

Omoboriowo et al, 2012 showed that environment of deposition affects reservoir Petrophysical properties using a suit of geophysical well logs for the Niger Delta. The objective of this paper is to integrate seismic and well log data for hydrocarbon volumetric analysis in D-One Field of the Niger delta region of Nigeria for prospect identification and reservoir characterization. Abraham-Adejumo (2013) used a suite of geophysical wire-line logs from an oil field in Niger Delta for the purpose of Well correlation and petrophysical analysis of "Rickie" field onshore Niger Delta the results showed a sand - shale inter-bedding of the subsurface stratigraphy with hydrocarbon bearing reservoirs (L, P and S), at depths of 2,943m,
$3,248 \mathrm{~m}$ and $3935 \mathrm{~m}$. Ihianle et al. (2013) used three dimensional seismic/well logs to carry out the structural interpretation over ' $\mathrm{X}-\mathrm{Y}$ ' field in the Niger Delta area of Nigeria. The seismic section and structure map revealed fault assisted closures at the center of the field, which correspond to the crest of rollover anticlines and which served as the trapping medium.

The estimated volume of hydrocarbon in place is 289 , 227,007 bbl (37,281acre-ft) of oil. Integrated 3D seismic and petrophysical data was employed by Edigbue et al. (2014) to evaluate hydrocarbon of 'Keke' field in the Niger Delta. Two sand units (S1 and S2) which existed between $9127 \mathrm{ft}$ and $11152 \mathrm{ft}$ were correlated and mapped using gamma ray log. The results obtained from the analysis of this field shows that the trapping mechanisms and the petrophysical parameters in 'Keke' field are favourable for hydrocarbon accumulation.

\section{MATERIALS AND METHODS}

Study Area: The precise location of the study area (fig. 1) was not disclosed in line with current practices by petroleum industries in Nigeria. The D-One field lies within the province of the Niger Delta basin bounded to the North, South, North West and North East by the Anambra, Gulf of Guinea, Benin and Calabar Flanks respectively. 


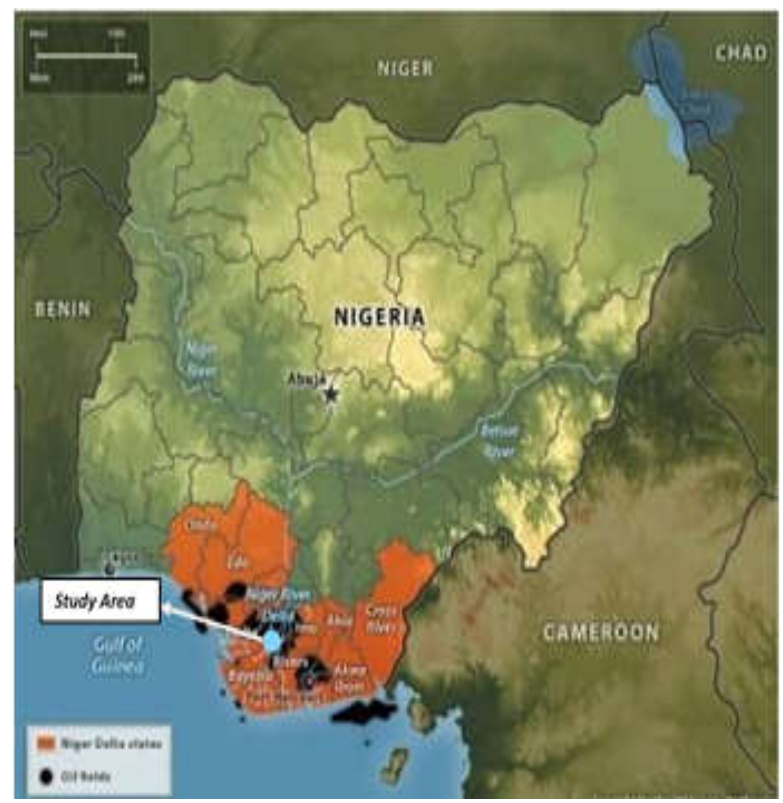

Fig 1: Map of Nigeria, showing the study area in the Niger Delta.
3D seismic volume in segy format, Seven composite well logs comprising of gamma ray (GR), resistivity (RT), neutron (NPHI), density (RHOB) and sonic (DT) as well as check shots data recorded at various locations within the D-One Field, Niger Delta was provided by Shell Petroleum Development Company (SPDC), Nigeria. The data was studied using the PETREL TM workflow.

\section{RESULTS AND DISCUSSION}

Well Log Correlation: The analysis of the all the well section revealed that each of the sand units (interval coloured yellow) extends through the field and varies in thickness with some unit occurring at greater depth than their adjacent unit i.e. possibly an evidence of faulting. The shale layers (interval coloured grey) were observed to increase with depth along with a corresponding decrease in sand layers. This pattern in the Niger Delta indicates transition from Benin to Agbada formation (Amigun, 2013). (Google)

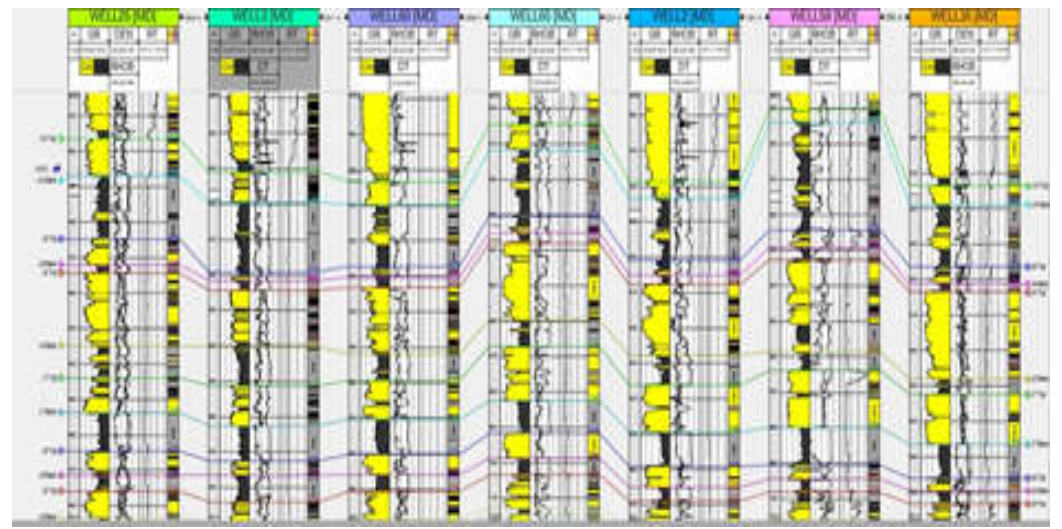

Fig 2: Well correlation panel across all wells showing the tops and base of reservoir J5-J10

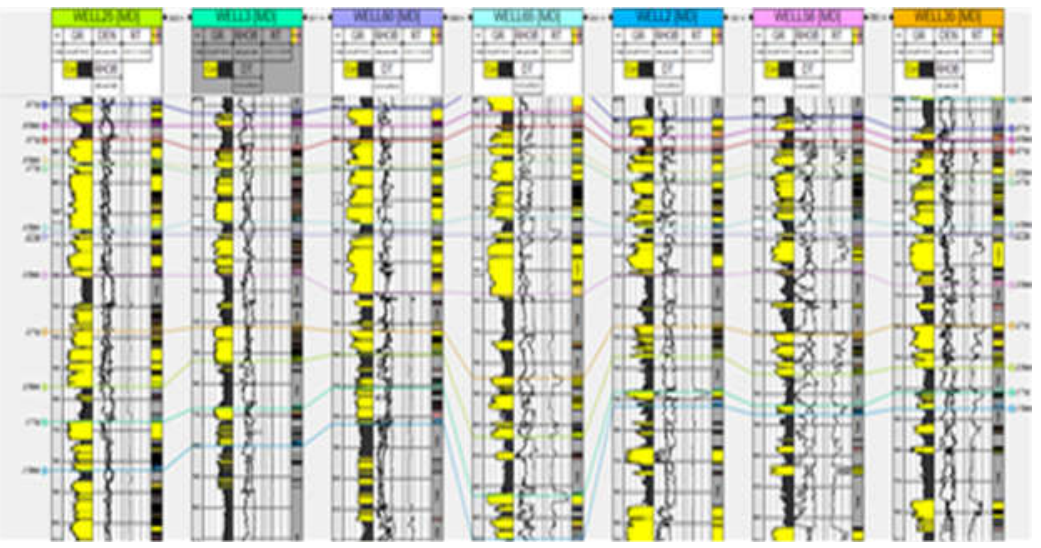

Fig 3: Well correlation panel across all wells showing the tops and base of reservoir J1-J5

Seismic To Well Tie: Well 25 check shot was used for the seismic to well tie to ensure that there was accurate tie between the well and seismic event. It aided in mapping the delineated hydrocarbon bearing reservoirs on the seismic data. Horizons were picked at the top of the mapped reservoirs and tied to the seismic data. A good tie was obtained between the synthetic seismogram and the seismic data. Figure 4 shows the synthetic seismogram for well 25 of the field. 


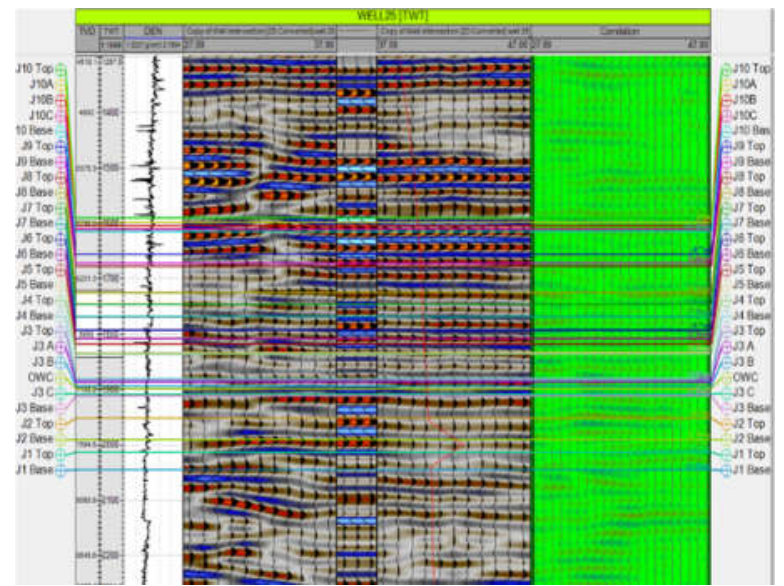

Fig 4: Showing well 25 seismic to well tie

Horizon and Fault Interpretation: Figure 5: Shows the mapped nine faults (fault 1- fault 9) and ten horizons (J1-J10) across the reservoirs. This was achieved after the seismic to well tie and the synthetic seismogram was done. The reservoirs of interest mapped are the J3 and J10 sands. Figure 4 clearly shows some of the faults observed in the seismic.

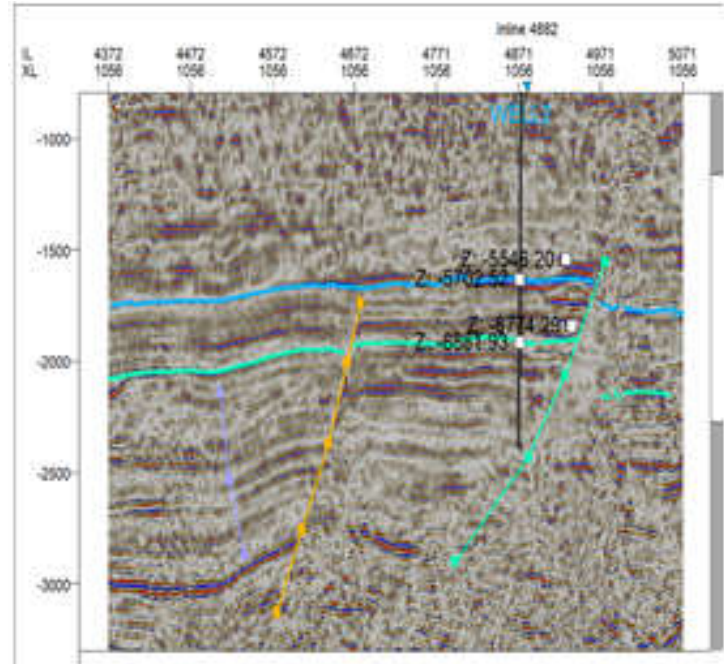

Fig 5: Showing 2 horizons picked and faults interpreted

Time and Depth Structural Maps: Mapped horizons and the generated fault polygons were used to generate grid maps which were in turn used to generate the time and depth structural map for horizons J10 and J3 as seen in Figures 6 and 7. The top and base maps for the two mapped horizons were created using the depth maps. Faults on the seismic section is also shown on the surfaces below in Figures 5 and 6.
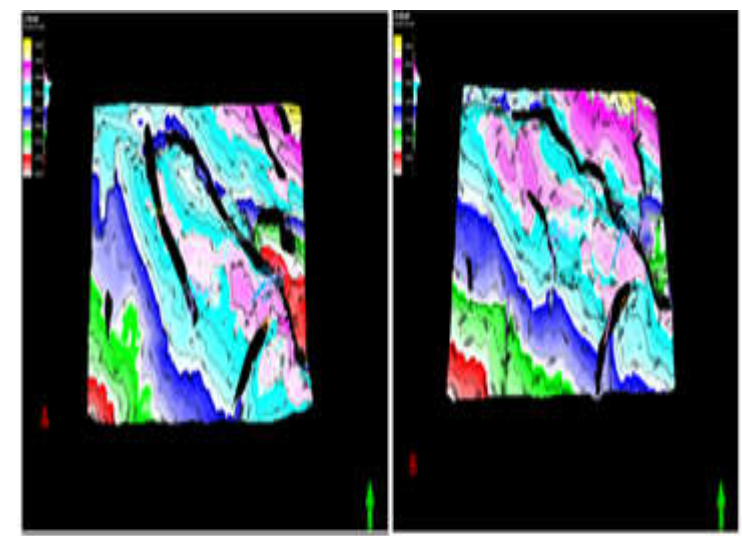

Fig 6: (A) and (B) Showing the Time Map for Horizons J10 and J3 respectively
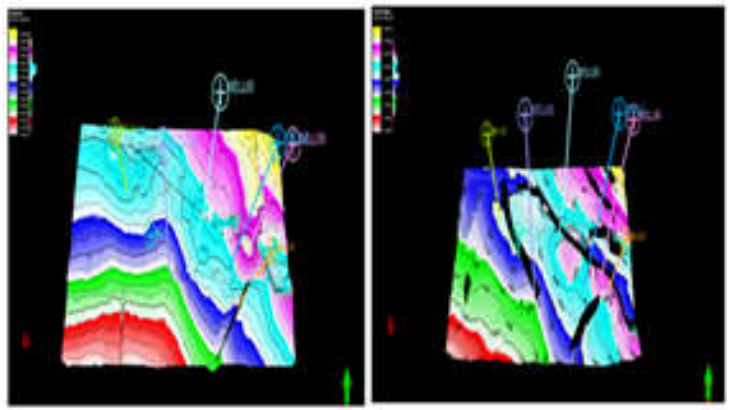

Fig 7: (A) and (B) showing the Depth maps generated for Horizons $\mathrm{J} 10$ and $\mathrm{J} 3$ respectively.

Facie Modelling: Using the Top and Base maps generated from the Depth map, static modelling was done to model the facie property in stochastic and deterministic probability conditions for the two mapped horizons, the results are displayed in figures 8 and 9. Facie recognized where Coarse Sand, Medium Sand, Fine Sand and Shale.
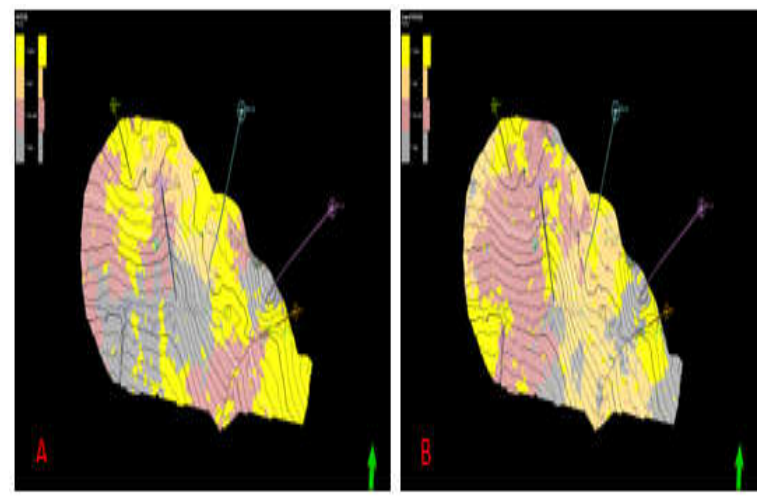

Fig 8 (A) and (B) Showing the Facie Models for horizon J10 in stochastic and deterministic probability conditions respectively 

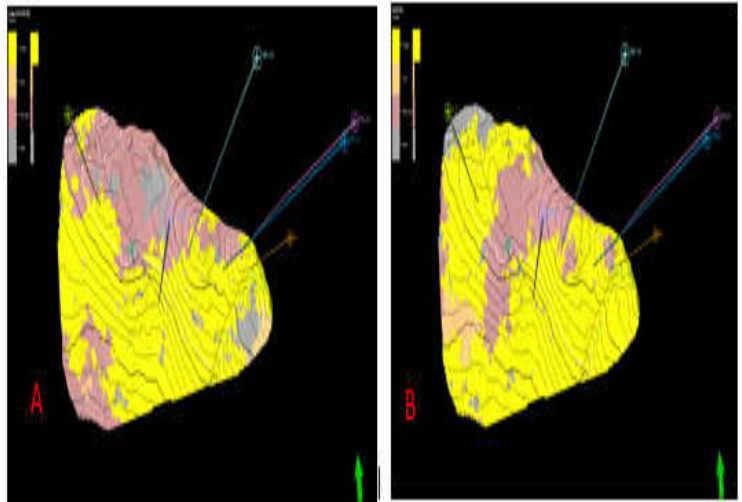

Fig 9 (A) and (B) Showing the Facie Models for horizon J3 in stochastic and deterministic probability conditions respectively

Petrophysical Modelling: The properties modelled are the Net-to-Gross (NTG), effective porosity, water saturation and permeability for both the deterministic and stochastic probability conditions. The models show the distribution of each parameter across the reservoir as shown in Figures 10 to 16
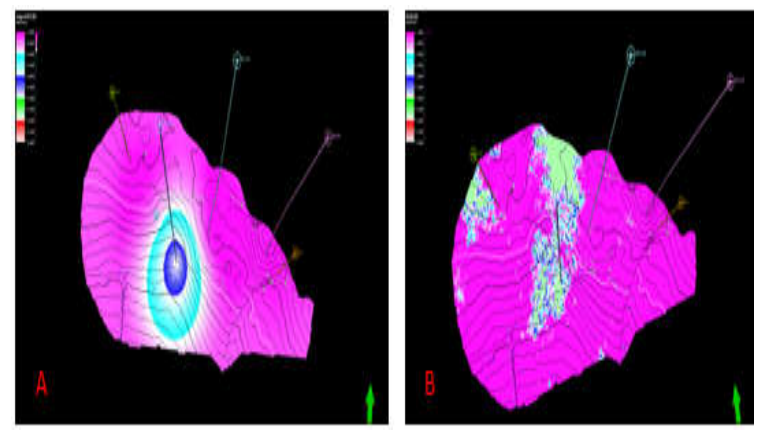

Figure 10 (A) and (B) Showing the Net to Gross distribution of sands across $\mathrm{J} 10$ reservoir in deterministic and stochastic probability conditions respectively

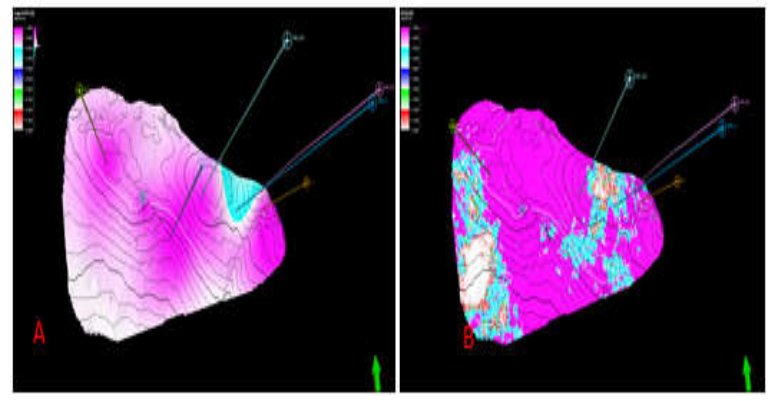

Fig 11 (A) and (B) Showing the Net to Gross distribution of sands across J3 reservoir in deterministic and stochastic probability conditions respectively
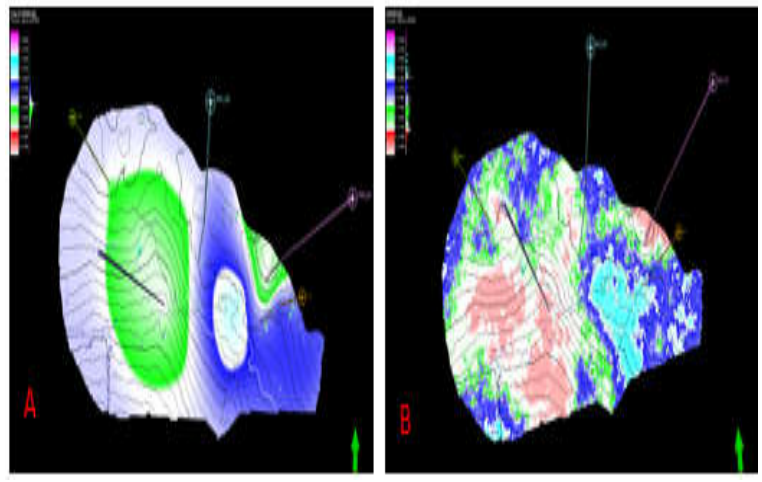

Fig 12 (A) and (B) Showing the distribution of porosities across J10 reservoir in deterministic and stochastic probability conditions respectively
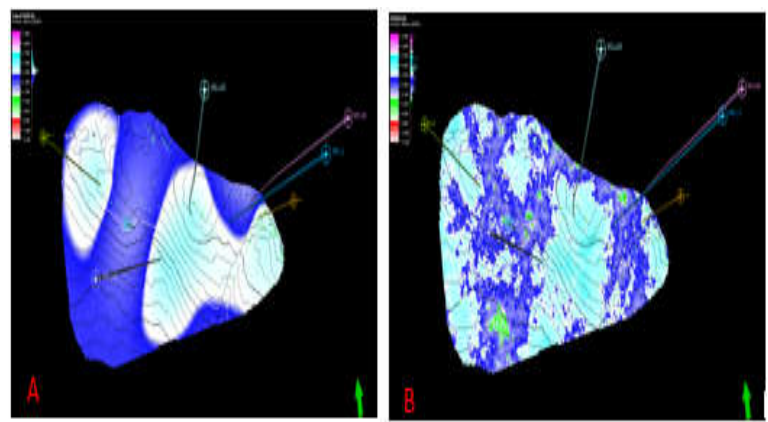

Fig 13 (A) and (B) Showing the distribution of porosities across J3 reservoir in deterministic and stochastic probability conditions respectively
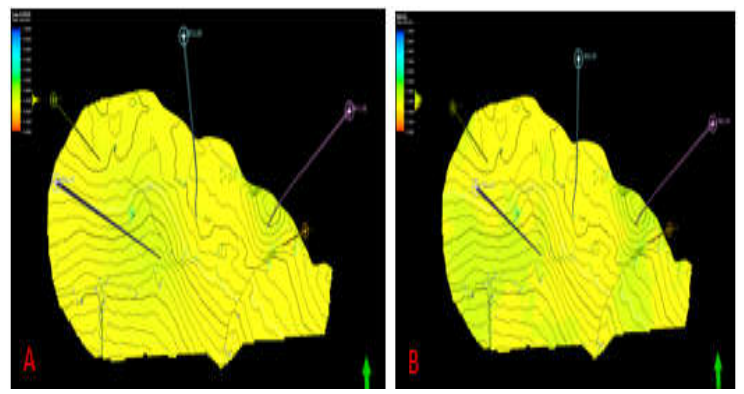

Fig 14 (A) and (B) Showing the water saturation distribution across $\mathrm{J} 10$ reservoir in deterministic and stochastic probability conditions respectively
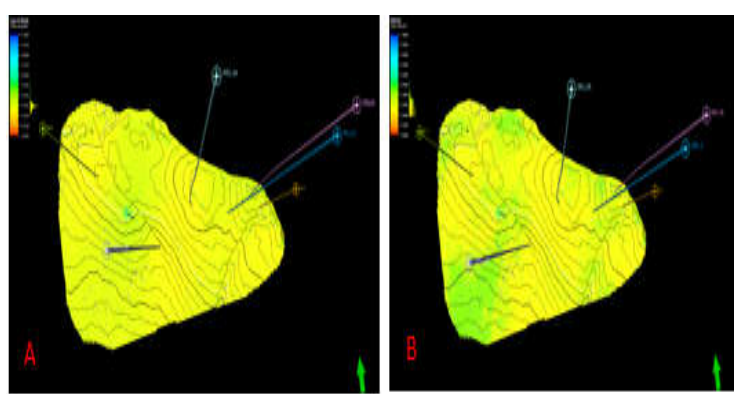

Fig 15 (A) and (B) Showing the water saturation distribution across J3 reservoir in deterministic and stochastic probability conditions respectively 

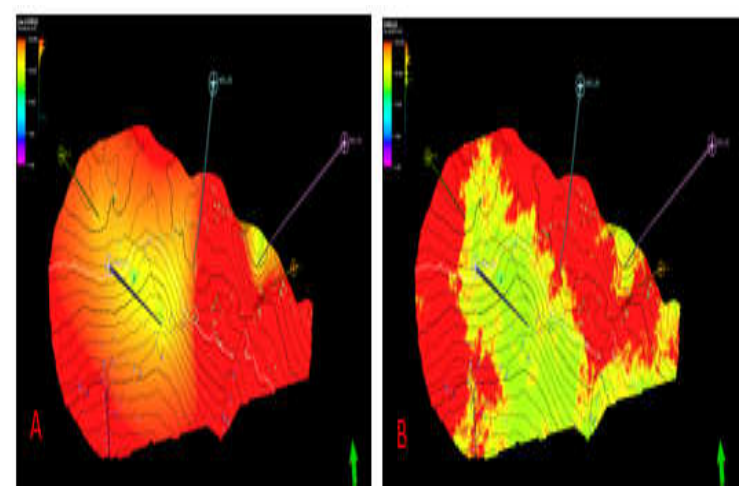

Fig 16 (A) and (B) Showing the permeability distribution across J10 reservoir in deterministic and stochastic probability conditions respectively.
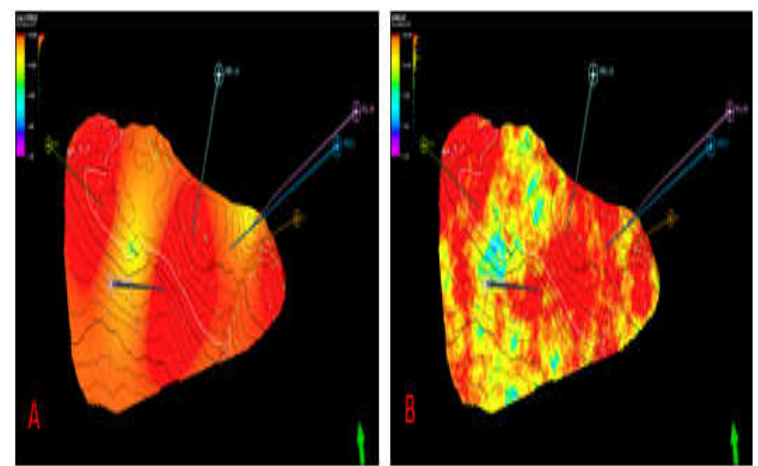

Fig 17 (A) and (B) Showing the permeability distribution across J3 reservoir in deterministic and stochastic probability conditions respectively.

Delineation of Fluid Contacts: Fluid contacts where picked on the well section using the Gamma ray, resistivity and the Neutron-Density logs. The oil water contact (OWC) was picked at the lowest point across the mapped horizons at approximately $-5862 \mathrm{ft}$ for reservoir $\mathrm{J} 10$ and $-7097 \mathrm{ft}$ for reservoir $\mathrm{J} 3$ as shown in Figure $18 \mathrm{~A}$ and $\mathrm{B}$. These contacts were modelled and the distribution of the Hydrocarbon across the reservoirs are shown in Figure 19 and 20. Across the 7 drilled wells, ten reservoir bodies J1 to J10 were identified, but two reservoirs $\mathrm{J} 3$ and $\mathrm{J} 10$ were analyzed. The $\mathrm{J} 3$ reservoir occurred at a depth range of $6775-7289 \mathrm{ft}$ with an average gross thickness of $140.14 \mathrm{ft}$, net thickness of $89.49 \mathrm{ft}$ and a net to gross of $61.62 \%$. The average total and effective porosity values are $0.27(27 \%)$ and $0.20(20 \%)$ respectively in the reservoir. The average permeability obtained was $4435.56 \mathrm{mD}$ with an average water saturation of 0.33 and an average volume of shale of 0.35 . Accordingly, the J10 reservoir occurs at a top and bottom depth range of 5546 and $5989 \mathrm{ft}$ respectively. The average gross and net thickness for the $\mathrm{J} 10$ reservoir gotten were 65 and $55.78 \mathrm{ft}$ respectively. The average values of the total and effective porosity estimated were $0.3188(31.9 \%)$ and $0.2887(28.9 \%)$ thus giving rise to an average permeability and water saturation of
$4160.45 \mathrm{mD}$ and 0.26 respectively. The probable average volume of shale was 0.12 and an excellent average net to gross of $0.899(90 \%)$. This result is presented in Table 8 and 9.
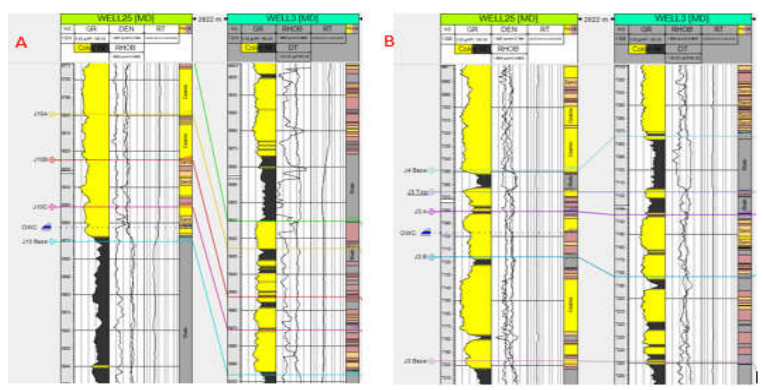

Fig 18 (A) and (B) showing Oil- Water contact (OWC) picked on the well logs for reservoirs $\mathrm{J} 10$ and $\mathrm{J} 3$ respectively

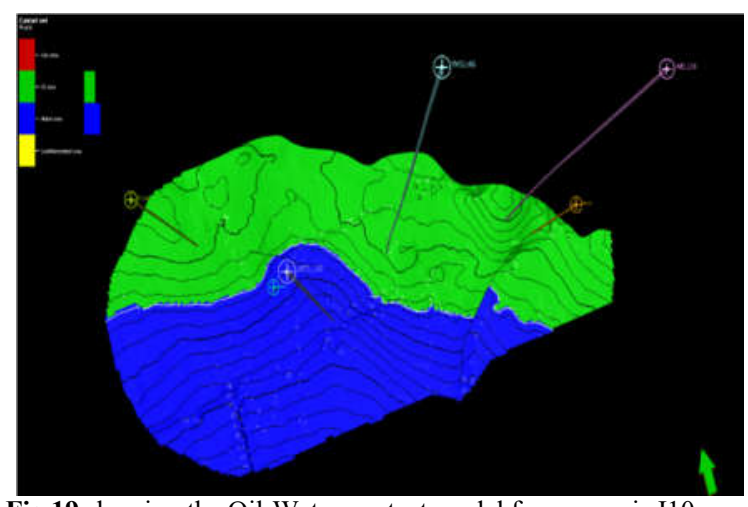

Fig 19 showing the Oil-Water contact model for reservoir J10

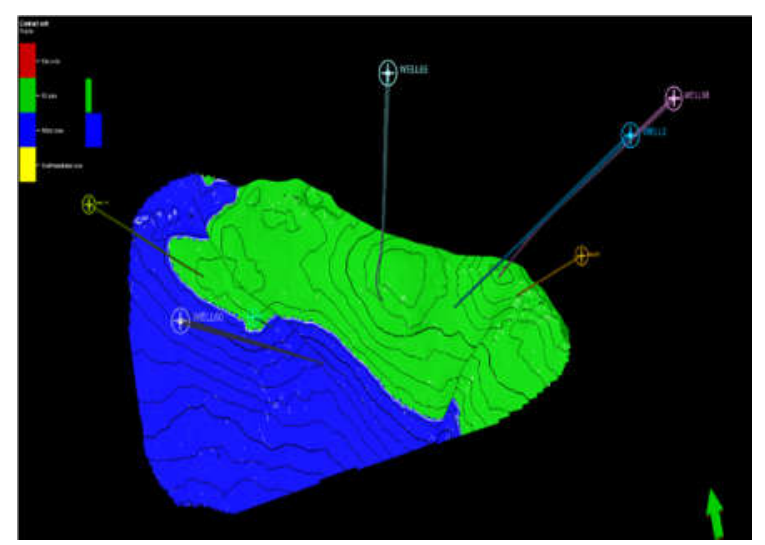

Fig 20 showing the Oil-Water contact model for reservoir J3.

Data Analysis: Formation evaluation involves examining a formation to detect the presence of hydrocarbon in commercial quantities by critically assessing a reservoir in terms of area, thickness, hydrocarbon presence, water saturation and porosity which would help estimate the volume of hydrocarbon in place (Hasbiantoro, 2014). The values displayed in tables 1 to 7 are the average values of the results obtained from the Petrophysical analysis of each reservoir in the 7 wells. 
Table 1: showing the Petrophysical evaluation across J1-J10 reservoir in well 2.

\begin{tabular}{|c|c|c|c|c|c|c|c|c|c|c|}
\hline Zone & Top (MD) & Base (MD) & Gross (MD) & Net (MD) & $\phi \mathrm{t}$ & de & NTG & $\mathrm{Sw}$ & Perm $(\mathrm{mD})$ & Vsh \\
\hline J1 & 7391 & 7436 & 45 & 0.97 & 0.17 & -0.01 & 0.02 & 0.48 & 113.71 & 1.09 \\
\hline $\mathrm{J} 2$ & 7181 & 7277 & 96 & 20.78 & 0.2 & 0.08 & 0.22 & 0.41 & 142.11 & 0.64 \\
\hline $\mathrm{J} 3$ & 6883 & 7012 & 129 & 71.45 & 0.25 & 0.17 & 0.55 & 0.35 & 5866.35 & 0.44 \\
\hline $\mathrm{J} 4$ & 6701 & 6858 & 157 & 98.37 & 0.28 & 0.21 & 0.63 & 0.32 & 4022.75 & 0.33 \\
\hline J5 & 6604 & 6680 & 76 & 45.4 & 0.28 & 0.21 & 0.59 & 0.33 & 3883.33 & 0.4 \\
\hline J6 & 6508 & 6566 & 58 & 0 & 0.17 & -0 & 0 & 0.48 & 0.04 & 1.01 \\
\hline J7 & 6276 & 6411 & 135 & 58.56 & 0.27 & 0.18 & 0.43 & 0.35 & 10481.54 & 0.54 \\
\hline J8 & 5992 & 6193 & 201 & 120.4 & 0.29 & 0.23 & 0.59 & 0.33 & 14489.05 & 0.38 \\
\hline J9 & 5926 & 5967 & 41 & 14.64 & 0.21 & 0.14 & 0.35 & 0.39 & 124.04 & 0.51 \\
\hline$J 10$ & 5702 & 5750 & 48 & 48 & 0.34 & 0.33 & 1 & 0.24 & 4263.12 & 0.04 \\
\hline
\end{tabular}

Table 2: showing the Petrophysical evaluation across J1-J10 reservoir in well 3.

\begin{tabular}{|c|c|c|c|c|c|c|c|c|c|c|}
\hline \multicolumn{11}{|l|}{ Well 3} \\
\hline Zone & Top (MD) & Base (MD) & Gross (MD) & Net (MD) & $\phi t$ & фe & NTG & $\mathrm{Sw}$ & Perm (mD) & Vsh \\
\hline $\mathrm{J} 1$ & 7583 & 7702 & 119 & 27.88 & 0.2 & 0.07 & 0.23 & 0.42 & 100.42 & 0.67 \\
\hline $\mathrm{J} 2$ & 7322 & 7427 & 105 & 18.91 & 0.2 & 0.08 & 0.18 & 0.42 & 55.39 & 0.62 \\
\hline $\mathrm{J} 3$ & 7021 & 7154 & 133 & 77.21 & 0.23 & 0.15 & 0.58 & 0.36 & 217.87 & 0.38 \\
\hline J4 & 6822 & 6978 & 156 & 89.21 & 0.23 & 0.16 & 0.57 & 0.35 & 131.53 & 0.33 \\
\hline J5 & 6748 & 6804 & 56 & 16.85 & 0.21 & 0.1 & 0.3 & 0.4 & 63.36 & 0.54 \\
\hline J6 & 6632 & 6670 & 38 & 0 & 0.17 & 0.03 & 0 & 0.46 & 0.02 & 0.85 \\
\hline J7 & 6420 & 6532 & 112 & 11.95 & 0.19 & 0.06 & 0.11 & 0.43 & 22.37 & 0.69 \\
\hline J8 & 6151 & 6311 & 160 & 62.31 & 0.22 & 0.12 & 0.38 & 0.38 & 153.08 & 0.51 \\
\hline J9 & 6110 & 6126 & 16 & 0 & 0.18 & 0.05 & 0 & 0.44 & 0.21 & 0.73 \\
\hline $\mathrm{J} 10$ & 5821 & 5905 & 84 & 46.22 & 0.23 & 0.15 & 0.55 & 0.36 & 156.97 & 0.35 \\
\hline
\end{tabular}

Table 3: showing the Petrophysical evaluation across J1-J10 reservoir in well 25.

\begin{tabular}{lllllllllll}
\hline \multicolumn{2}{l}{ Well 25 } & & & & & & & & & \\
Zone & Top (MD) & Base (MD) & Gross (MD) & Net (MD) & $\phi t$ & $\phi e$ & NTG & Sw & Perm (mD) & Vsh \\
J1 & 7585 & 7743 & 158 & 73.53 & 0.27 & 0.2 & 0.46 & 0.34 & 4369.35 & 0.37 \\
J2 & 7292 & 7472 & 180 & 150.16 & 0.28 & 0.24 & 0.83 & 0.29 & 2174.73 & 0.18 \\
J3 & 6978 & 7110 & 132 & 115.13 & 0.29 & 0.25 & 0.87 & 0.29 & 1973.59 & 0.16 \\
J4 & 6757 & 6963 & 206 & 190.07 & 0.3 & 0.26 & 0.92 & 0.28 & 2531.01 & 0.14 \\
J5 & 6674 & 6746 & 72 & 30.57 & 0.24 & 0.15 & 0.42 & 0.36 & 806.07 & 0.44 \\
J6 & 6559 & 6628 & 69 & 0 & 0.17 & 0.03 & 0 & 0.45 & 0.42 & 0.84 \\
J7 & 6354 & 6452 & 98 & 29.69 & 0.21 & 0.1 & 0.3 & 0.39 & 107.67 & 0.53 \\
J8 & 6058 & 6264 & 206 & 171.16 & 0.3 & 0.26 & 0.83 & 0.28 & 3608.38 & 0.17 \\
J9 & 5962 & 6036 & 74 & 10.85 & 0.2 & 0.08 & 0.15 & 0.42 & 24.71 & 0.59 \\
J10 & 5680 & 5785 & 105 & 78.25 & 0.26 & 0.21 & 0.75 & 0.32 & 1166.09 & 0.25 \\
\hline
\end{tabular}

Table 4: showing the Petrophysical evaluation across J1-J10 reservoir in well 35.

\begin{tabular}{|c|c|c|c|c|c|c|c|c|c|c|}
\hline \multicolumn{11}{|c|}{ Well 35} \\
\hline Zone & Top (MD) & Base (MD) & Gross (MD) & Net (MD) & $\phi \mathrm{t}$ & фe & NTG & Sw & Perm (mD) & Vsh \\
\hline $\mathrm{J} 1$ & 7317 & 7370 & 53 & 15.7 & 0.21 & 0.07 & 0.29 & 0.42 & 232.22 & 0.72 \\
\hline $\mathrm{J} 2$ & 7100 & 7238 & 138 & 62.55 & 0.23 & 0.14 & 0.45 & 0.37 & 442.46 & 0.43 \\
\hline $\mathrm{J} 3$ & 6807 & 6970 & 163 & 122.25 & 0.28 & 0.23 & 0.75 & 0.31 & 2605.8 & 0.23 \\
\hline $\mathrm{J} 4$ & 6635 & 6775 & 140 & 87.35 & 0.26 & 0.21 & 0.62 & 0.32 & 1622.82 & 0.25 \\
\hline J5 & 6536 & 6610 & 74 & 27.63 & 0.23 & 0.14 & 0.37 & 0.37 & 761.37 & 0.48 \\
\hline J6 & 6465 & 6500 & 35 & 0 & 0.19 & 0.07 & 0 & 0.42 & 0.88 & 0.6 \\
\hline J7 & 6230 & 6369 & 139 & 95.31 & 0.28 & 0.23 & 0.68 & 0.31 & 2842.04 & 0.25 \\
\hline J8 & 5941 & 6184 & 243 & 173.28 & 0.31 & 0.26 & 0.71 & 0.29 & 5115.08 & 0.21 \\
\hline J9 & 5867 & 5920 & 53 & 34.35 & 0.25 & 0.19 & 0.65 & 0.33 & 578.71 & 0.25 \\
\hline $\mathrm{J} 10$ & 5642 & 5695 & 53 & 53 & 0.32 & 0.32 & 1 & 0.24 & 3749.25 & 0.05 \\
\hline
\end{tabular}

Table 5: showing the Petrophysical evaluation across J1-J10 reservoir in well 58.

\begin{tabular}{|c|c|c|c|c|c|c|c|c|c|c|}
\hline Zone & Top (MD) & Base (MD) & Gross (MD) & Net (MD) & $\phi \mathrm{t}$ & фe & NTG & Sw & Perm (mD) & Vsh \\
\hline $\mathrm{J} 1$ & 7272 & 7296 & 24 & 7.68 & 0.21 & 0.09 & 0.32 & 0.41 & 91.44 & 0.57 \\
\hline $\mathrm{J} 2$ & 7065 & 7182 & 117 & 76.35 & 0.24 & 0.17 & 0.65 & 0.34 & 459.34 & 0.32 \\
\hline $\mathrm{J} 3$ & 6775 & 6886 & 111 & 23.78 & 0.21 & 0.07 & 0.21 & 0.42 & 453.13 & 0.74 \\
\hline $\mathrm{J} 4$ & 6592 & 6731 & 139 & 81.41 & 0.25 & 0.16 & 0.58 & 0.35 & 904.25 & 0.44 \\
\hline J5 & 6500 & 6569 & 69 & 13.8 & 0.21 & 0.12 & 0.2 & 0.38 & 164.59 & 0.45 \\
\hline $\mathrm{J} 6$ & 6432 & 6468 & 36 & 25.29 & 0.28 & 0.23 & 0.7 & 0.31 & 1736.88 & 0.25 \\
\hline J7 & 6195 & 6338 & 143 & 34.75 & 0.21 & 0.07 & 0.24 & 0.42 & 182.68 & 0.69 \\
\hline $\mathrm{J} 8$ & 5917 & 6147 & 230 & 52.77 & 0.21 & 0.11 & 0.23 & 0.39 & 44.91 & 0.5 \\
\hline J9 & 5845 & 5888 & 43 & 43 & 0.32 & 0.29 & 1 & 0.25 & 2108.11 & 0.07 \\
\hline J10 & 5546 & 5579 & 33 & 33 & 0.32 & 0.29 & 1 & 0.25 & 2685.55 & 0.07 \\
\hline
\end{tabular}


Table 6: showing the Petrophysical evaluation across J1-J10 reservoir in well 60.

\begin{tabular}{|c|c|c|c|c|c|c|c|c|c|c|}
\hline \multicolumn{11}{|c|}{ Well 60} \\
\hline Zone & Top (MD) & Base (MD) & Gross (MD) & Net (MD) & $\phi \mathrm{t}$ & de & NTG & $\mathrm{Sw}$ & Perm (mD) & Vsh \\
\hline $\mathrm{J} 1$ & 7600 & 7716 & 116 & 34.7 & 0.22 & 0.14 & 0.29 & 0.37 & 60.79 & 0.38 \\
\hline $\mathrm{J} 2$ & 7417 & 7490 & 73 & 16.77 & 0.21 & 0.12 & 0.22 & 0.38 & 61.86 & 0.44 \\
\hline $\mathrm{J} 3$ & 7103 & 7289 & 186 & 145.21 & 0.35 & 0.31 & 0.78 & 0.26 & 12668.14 & 0.14 \\
\hline $\mathrm{J} 4$ & 6892 & 7066 & 174 & 137.21 & 0.31 & 0.27 & 0.78 & 0.28 & 4857.85 & 0.15 \\
\hline J5 & 6799 & 6877 & 78 & 57.26 & 0.32 & 0.28 & 0.73 & 0.28 & 8811.63 & 0.17 \\
\hline $\mathrm{J} 6$ & 6691 & 6751 & 60 & 11.8 & 0.23 & 0.15 & 0.19 & 0.36 & 853.93 & 0.35 \\
\hline J7 & 6485 & 6596 & 111 & 35.67 & 0.22 & 0.13 & 0.32 & 0.37 & 216.65 & 0.42 \\
\hline J8 & 6222 & 6410 & 188 & 84.55 & 0.25 & 0.18 & 0.45 & 0.34 & 3034.9 & 0.31 \\
\hline J9 & 6163 & 6195 & 32 & 22.3 & 0.27 & 0.22 & 0.69 & 0.31 & 1208.24 & 0.21 \\
\hline $\mathrm{J} 10$ & 5924 & 5989 & 65 & 65 & 0.35 & 0.34 & 1 & 0.23 & 5362.57 & 0.04 \\
\hline
\end{tabular}

Table 7: showing the Petrophysical evaluation across J1-J10 reservoir in well 65.

\begin{tabular}{|c|c|c|c|c|c|c|c|c|c|c|}
\hline & & & & & & & & & & \\
\hline Zone & Top (MD) & Base (MD) & Gross (MD) & Net (MD) & $\phi \mathrm{t}$ & фe & NTG & $\mathrm{Sw}$ & Perm (mD) & Vsh \\
\hline $\mathrm{J} 1$ & 7319 & 7364 & 45 & 15.65 & 0.25 & 0.15 & 0.34 & 0.37 & 3614.83 & 0.52 \\
\hline $\mathrm{J} 2$ & 7146 & 7241 & 95 & 84.11 & 0.29 & 0.25 & 0.88 & 0.28 & 1568.51 & 0.14 \\
\hline $\mathrm{J} 3$ & 6867 & 6994 & 127 & 71.44 & 0.29 & 0.23 & 0.56 & 0.32 & 7264.04 & 0.35 \\
\hline $\mathrm{J} 4$ & 6689 & 6825 & 136 & 121.11 & 0.34 & 0.32 & 0.89 & 0.25 & 7056.03 & 0.1 \\
\hline $\mathrm{J} 5$ & 6595 & 6671 & 76 & 9.87 & 0.19 & 0.06 & 0.13 & 0.43 & 57.67 & 0.68 \\
\hline J6 & 6495 & 6556 & 61 & 61 & 0.41 & 0.39 & 1 & 0.22 & 21910.85 & 0.04 \\
\hline J7 & 6281 & 6417 & 136 & 57.57 & 0.27 & 0.19 & 0.42 & 0.35 & 6346.18 & 0.39 \\
\hline $\mathrm{J} 8$ & 6013 & 6213 & 200 & 81.59 & 0.23 & 0.15 & 0.41 & 0.36 & 458.36 & 0.38 \\
\hline J9 & 5940 & 5985 & 45 & 39.13 & 0.31 & 0.28 & 0.86 & 0.27 & 2790.97 & 0.12 \\
\hline$J 10$ & 5695 & 5762 & 67 & 67 & 0.37 & 0.35 & 1 & 0.23 & 11739.59 & 0.05 \\
\hline
\end{tabular}

\begin{tabular}{|c|c|c|c|c|c|c|c|c|c|c|}
\hline \multicolumn{11}{|c|}{ Reserviour J3 } \\
\hline Zone & Top (MD) & Base (MD) & Gross (MD) & Net (MD) & $\phi t$ & фe & NTG & Sw & Perm (mD) & Vsh \\
\hline 2 & 6883 & 7012 & 129 & 71.44 & 0.25 & 0.17 & 0.55 & 0.35 & 5866.36 & 0.44 \\
\hline 3 & 7021 & 7154 & 133 & 77.2 & 0.23 & 0.15 & 0.58 & 0.36 & 217.87 & 0.38 \\
\hline 25 & 6978 & 7111 & 132 & 115.12 & 0.29 & 0.25 & 0.87 & 0.29 & 1973.59 & 0.16 \\
\hline 35 & 6807 & 6970 & 163 & 122.25 & 0.28 & 0.23 & 0.75 & 0.3 & 2605.8 & 0.23 \\
\hline 58 & 6775 & 6886 & 111 & 23.78 & 0.2 & 0.07 & 0.21 & 0.42 & 453.13 & 0.75 \\
\hline 60 & 7103 & 7289 & 186 & 145.21 & 0.34 & 0.31 & 0.78 & 0.26 & 12668.14 & 0.14 \\
\hline \multirow[t]{2}{*}{65} & 6867 & 6994 & 127 & 71.43 & 0.29 & 0.23 & 0.56 & 0.31 & 7264.03 & 0.35 \\
\hline & & Average & 140.14 & 89.49 & 0.27 & 0.20 & 0.61 & 0.33 & 4435.56 & 0.35 \\
\hline
\end{tabular}

Table 9: Showing the average values for the Petrophysical properties in reservoir J10.

\begin{tabular}{lllllllllll}
\multicolumn{2}{l}{ Reservoir 10 } \\
\hline Wells & Top (MD) & Base (MD) & Gross (MD) & Net (MD) & фt & de & NTG & Sw & Perm (mD) & Vsh \\
2 & 5702 & 5750 & 48 & 48 & 0.34 & 0.33 & 1 & 0.23 & 4263.12 & 0.04 \\
3 & 5821 & 5905 & 84 & 46.22 & 0.23 & 0.15 & 0.55 & 0.36 & 156.97 & 0.35 \\
25 & 5680 & 5785 & 105 & 78.25 & 0.26 & 0.21 & 0.74 & 0.31 & 1166.09 & 0.24 \\
35 & 5642 & 5695 & 53 & 53 & 0.33 & 0.32 & 1 & 0.24 & 3749.25 & 0.05 \\
58 & 5546 & 5579 & 33 & 33 & 0.32 & 0.29 & 1 & 0.25 & 2685.55 & 0.07 \\
60 & 5924 & 5989 & 65 & 65 & 0.35 & 0.34 & 1 & 0.23 & 5362.57 & 0.04 \\
65 & 5695 & 5762 & 67 & 67 & 0.37 & 0.35 & 1 & 0.22 & 11739.59 & 0.04 \\
\hline
\end{tabular}

Table 10: Input Data for the Volumetric analysis for Reservoir J10

\begin{tabular}{ll} 
Net to Gross & 0.89 \\
Porosity & 0.28 \\
Water saturation & 0.26 \\
Formation Volume Factor & 1.25 \\
Recovery factor & 0.35 \\
Oil Water Contact (OWC) & $-7097 \mathrm{ft}$ \\
\hline
\end{tabular}

Table 11: Output result for both stochastic and deterministic volumetric estimation for Reservoir J10

\begin{tabular}{ll}
\hline Stochastic Model For Volumetrics For Reservoir J10 \\
\hline STOIIP[*10 6 STB] & Recoverable oil[*10'6 STB] \\
651 & 228 \\
Deterministic Model For Volumetrics For Reservoir J10 \\
STOIIP[*10 6 STB] & Recoverable oil[ $\left[{ }^{*} 10^{*} 6\right.$ STB] \\
614 & 215 \\
\hline
\end{tabular}

For the Volumetric analysis, the parameters used in the estimation of Stock Tank Oil Initially in Place (STOIIP) were generated using the Petrel Software. The imputed data were the average values obtained from the comprehensive petrophysics of the reservoirs of interest. Table 4.10 to 4.13 shows the result or outcome realized for the $\mathrm{J} 10$ and $\mathrm{J} 3$ reservoirs in both the stochastic and deterministic probability conditions.

Two hydrocarbon reservoirs were delineated in the DOne field with varying sand unit thickness suggesting a possible occurrence of faults. The shale and sand layers, increased and decreased with depth respectively. Two reservoirs were identified as 
hydrocarbon bearing units from the Resistivity log across the 7 wells.

Table 12: Input Data for the Volumetric analysis for Reservoir J3

\begin{tabular}{ll} 
Net to Gross & 0.61 \\
Porosity & 0.21 \\
Water saturation & 0.33 \\
Formation Volume Factor & 1.25 \\
Recovery factor & 0.35 \\
Oil Water Contact (OWC) & $-5862 \mathrm{ft}$ \\
\hline
\end{tabular}

Table 13: Output result for both stochastic and deterministic volumetric estimation for Reservoir J3

\begin{tabular}{ll}
\hline Stochastic Model For Volumetrics For Reservoir J3 \\
\hline STOIIP $\left[* 10^{\wedge} 6 \mathrm{STB}\right]$ & Recoverable oil $\left[* 10^{\wedge} 6 \mathrm{STB}\right]$ \\
1054 & 369 \\
Deterministic Model For Volumetrics For Reservoir J3 \\
STOIIP $\left[* 10^{\wedge} 6 \mathrm{STB}\right]$ & Recoverable oil $\left[* 10^{\wedge} 6 \mathrm{STB}\right]$ \\
921 & 323 \\
\hline
\end{tabular}

Petrophysical analysis of the $\mathrm{J} 3$ and $\mathrm{J} 10$ reservoirs revealed average parameters as: water saturation $(0.26$ - 0.33), gross thickness (65 - 140ft), net thickness (55.78 - 89.49ft), net-to-gross (72 - 98\%), porosity (17 - 34.7\%), and permeability (4160.4 - $4435.56 \mathrm{mD})$. Tables 10 to 13 shows that reservoir $\mathrm{J} 10$ is more prolific than $\mathrm{J} 3$ within the D-One Field. Volumetric analysis estimates the volume of hydrocarbon in place to be $614 \mathrm{MMSTB}-1054 \mathrm{MMSTB}$ while recoverable oil is between 215-369MMSTB. These results evidently show that the D-One field, has an exploitable hydrocarbon potential.

Conclusion: Looking at the Petrophysical parameters that was obtained from the reservoir characterization using the well log and 3D seismic data available, we can infer that the two reservoirs mapped, correlated and modelled across the seven wells has a respectable hydrocarbon potential.

\section{REFERENCES}

Abraham-Adejumo, RM (2013). Well correlation and Petrophysical analysis, a case study of "Rickie" field onshore Niger Delta. The International Journal of Engineering and Science. 12(2): 94-99

Adetoye, TO; Enikanselu, PA (2009). Hydrocarbon reservoir mapping and volumetric analysis using seismic and borehole data over extreme field, South Western Niger Delta. Ozean Journal of Applied Sciences. 2(4): 429-431.

Aizebeokha, P; Olayinka, I (2011). Structural and stratigraphic mapping of Emi Field offshore Niger Delta. J Geol Min Res. 3(2):25-38

Edigbue, AA; Komolafe, AA; Adesida, OJ; Itamuko (2014). Hydrocarbon reservoir characterization of "Keke" field, Niger Delta using 3 seismic and Petrophysical data. American Journal of Scientific and Industrial Research. 5 (2) 73-80.

Ihianle OE; Alile OM; Azi, SO; Airen JO; Osuoji OU (2013). Three dimensional seismic/well logs and structural interpretation over ' $\mathrm{X}-\mathrm{Y}$ ' field in the Niger Delta area of Nigeria. Science and Technology. 3(2): 47-54.

Omoboriowo, AO; Chiaghanam, OI; Chiadikobi, KC; Oluwajana, OA; Soronnadi-Ononiwu CG; Ideozu, RU (2012). Reservoir characterization of Konga Field, Onshore Niger Delta, Southern Nigeria. Int. J Sci. Emerging Tech 3(1): 19-31. 